\title{
Indicaciones histórico-epistemológicas del uso de tecnologías digitales en la Educación Matemática brasileña
}

\author{
Victor Hugo Ricco Bone Antunes \\ antunesvictorh@gmail.com \\ https://orcid.org/0000-0002-4755-7645 \\ Clodis Boscarioli \\ clodis.boscarioli@unioeste.br \\ https://orcid.org/0000-0002-7110-2026 \\ Tiago Emanuel Klüber \\ tiagokluber@gmail.com \\ https://orcid.org/0000-0003-0971-6016
}

Universidade Estadual do Oeste do Paraná (Unioeste, Brasil)

Recibido: 15/03/2020 Aceptado: 12/07/2020

\begin{abstract}
Resumen
Este artículo señala los cambios que se han producido a lo largo de los años en la investigación relacionada con el uso pedagógico de las tecnologías digitales publicados en el ENEM (Encuentro Nacional de Educación Matemática) desde sus actas. Se analizaron 421 artículos publicados en las 12 ediciones del evento que tuvieron lugar entre 1987 y 2016 , divididos en comunicaciones científicas, informes de experiencias y carteles. Después de la lectura, se realizó un análisis aislado, presentando el enfoque de la investigación publicada en cada edición. En la secuencia, fue posible comparar las ediciones para observar los cambios más marcados que ocurrieron en las publicaciones a lo largo de la historia del evento. El cambio principal observado se refiere al enfoque de la investigación, que en las primeras ediciones se centró en mostrar formas de usar, de forma pedagógica, tecnologías digitales o presentar sistemas para las matemáticas, y en las últimas ediciones, más centradas en discutir cómo las tecnologías digitales se están insertando en el aula y cómo los maestros se están preparando para tal uso, desde la formación inicial hasta la continua.

Palabras clave: Educación Matemática; Cambios Histórico-epistemológicos; Tecnologías Digitales.
\end{abstract}

\section{Indícios histórico-epistemológicos do uso de tecnologias digitais na Educação Matemática brasileira}

\section{Resumo}

Este artigo aponta as mudanças histórico-epistemológicas que ocorreram ao longo dos anos em pesquisas relacionadas ao uso pedagógico das tecnologias digitais publicadas no ENEM (Encontro Nacional de Educação Matemática) a partir de seus Anais. Foram analisados 421 artigos publicados nas 12 edições do evento que ocorreram entre os anos de 1987 e 2016, divididos em comunicações científicas, relatos de experiência e pôsteres. Após a leitura, realizou-se uma análise isolada, apresentando o foco das pesquisas publicadas em cada edição. Na sequência, foi possível comparar as edições, de modo a observar as mudanças mais acentuadas que ocorreram nas publicações ao longo da história do evento, nos permitindo algumas inferências. A principal mudança observada se refere ao foco das pesquisas, que nas primeiras edições centrava-se em mostrar formas de utilizar, de forma 
pedagógica, as tecnologias digitais, ou apresentar sistemas para matemática, e nas últimas edições, mais voltado a discutir como as tecnologias digitais estão sendo inseridas em sala de aula e como os professores estão sendo preparados para tal utilização, desde a formação inicial à continuada.

Palavras-chave: Educação Matemática; Mudanças Histórico-epistemológicas; Tecnologias Digitais.

\title{
Historical-epistemological evidence of the use of digital technologies in brazilian Mathematical Education
}

\begin{abstract}
This paper points out the changes that have occurred over the years in research related to the pedagogical use of digital technologies published in ENEM (National Meeting of Mathematical Education) from its Annals. 421 papers published in the 12 editions of the event that took place between 1987 and 2016 were analyzed, divided into scientific communications, experience reports and posters. After reading, an isolated analysis was carried out, presenting the focus of the research published in each edition. In the sequence, it was possible to compare the editions, in order to observe the most marked changes that occurred in publications throughout the history of the event. The main change observed refers to the focus of research, which in the first editions focused on showing how the digital technologies was used, in a pedagogical way, or presenting systems to math, and in the latest editions, more focused on discussing how digital technologies they are being inserted in the classroom and how teachers are being prepared for such use from initial to continuing education.
\end{abstract}

Keywords: Mathematical Education; Historical-epistemological changes; Digital Technologies.

\section{Introdução}

O uso das Tecnologias Digitais da Informação de Comunicação (TDIC) vem ganhando mais espaço na Educação, seja na modalidade presencial, semipresencial ou à distância. Diversos docentes aderiram ao uso de ferramentas tecnológicas como um suporte ao conteúdo ensinado em sala, buscando dinamizar suas aulas na busca de tornar o conteúdo mais atrativo aos alunos (Antunes \& Cibotto, 2018).

Em decorrência da integração dessas tecnologias para o ensino, em especial o de Matemática, diversos pesquisadores, como Chiari e Borba (2016), Farias e Miskulin (2013), Salles e Bairral (2010), passaram a investigar sobre o uso dessas ferramentas digitais no ensino de Matemática, e a divulgar o resultado de suas pesquisas em eventos da área, como no Encontro Nacional de Educação Matemática (ENEM). Além de pesquisadores reconhecidos, há muitos professores e pesquisadores iniciantes que circularam pelas 12 edições do ENEM, que é o espaço de maior divulgação de práticas e pesquisas em Educação Matemática do Brasil. Apesar de ser um evento itinerante, bastante plural, e que a partir de 
sua terceira edição passou a ser realizado de forma trianual, é razoável afirmar que ele congrega, de modo articulado, traços paradigmáticos ou de estilo de pensamento da comunidade de Educadores Matemáticos, e pesquisadores da área. A noção de históricoepistemológico, neste texto, encontra respaldo na epistemologia fleckiana, a qual "valoriza o contexto histórico-psico-cultural da produção do conhecimento por um coletivo de cientistas" (Klüber, 2009, p. 222). Para o médico e sociólogo Ludwik Fleck (1886-1961), a construção do conhecimento não pode ser atribuída a um sujeito isolado, mas sim por um coletivo de cientistas (Klüber, 2009). Desse modo, os fatos científicos são assimilados e estilizados, ou seja, traduzidos em seu próprio estilo, por outros coletivos de pensamento. Tal tradução implica em modificação (Delizoicov et al., 2002, p. 59).

Nesse sentido, considerando que a produção de conhecimento no campo das tecnologias decorre de coletivos distintos daqueles da Educação Matemática, e que o conhecimento sobre tecnologia vem de fora para dentro, é plausível afirmar que no decorrer de mais de 30 anos ocorreram modificações no interior da comunidade de Educação Matemática, e particularmente, no caso do uso das TDIC no ensino de Matemática. Por isso, analisar os textos do evento, de um ponto de vista histórico-epistemológico, é pertinente para qualquer subárea da pesquisa em Educação Matemática, e, em nosso interesse particular, sobre as TDIC nas aulas de Matemática. Essa incursão permite compreender tendências que perderam força e identificar outras que podem contribuir para os avanços micro e marco da pesquisa nessa temática, também do ponto de vista da produção do conhecimento.

Além disso, inspirados nos trabalhos de Andrade e Nacarato (2004) que analisaram as tendências no ensino de Geometria nas sete primeiras edições do ENEM, e Barbosa et al. (2019), que analisaram pesquisas em Educação Estatística na décima segunda edição do mesmo evento, este trabalho tem por objetivo identificar as mudanças que ocorreram nas pesquisas ao longo da história do ENEM no que se refere à Educação Matemática e Tecnologias Digitais nas doze primeiras edições do evento, de 1987 a 2016, cujos Anais estão disponíveis no site da Sociedade Brasileira de Educação Matemática, SBEM ${ }^{1}$.

Este artigo segue assim organizado: a próxima seção traz a fundamentação da pesquisa, que aborda também alguns aspectos históricos relacionados ao início do uso das

\footnotetext{
${ }^{1}$ Para realização deste trabalho não foram consideradas as pesquisas publicadas na $13^{\mathrm{a}}$ edição do evento em 2019, ano de elaboração dessa pesquisa, uma vez que os Anais dessa edição foram disponibilizados apenas no início de 2020. Os Anais do ENEM podem ser acessados todos por meio do link: http://www.sbembrasil.org.br/sbembrasil/index.php/anais/enem.
} 
TDIC para o ensino e para o ensino de Matemática, seguida da metodologia adotada, das análises e resultados obtidos, e das considerações finais e perspectivas do trabalho.

\section{Tecnologias Digitais e a Educação (Matemática) Brasileira: breve excurso histórico}

No Brasil, assim como em outros países, a primeira tecnologia digital utilizada para fins educativos foi o computador. Segundo Valente (1999, p. 18), "o uso do computador na Educação teve início com algumas experiências em universidades, no princípio da década de 70”. Em 1971 "se discutiu o uso de computadores no ensino de Física, em seminário promovido pela Universidade de São Carlos, assessorado por um especialista da Universidade de Dartmouth/USA" (Moraes, 1993, p. 17). No mesmo ano, com a coordenação técnica da Universidade Federal de São Carlos (UFSCar), realizou-se, no Rio de Janeiro, a Primeira Conferência Nacional de Tecnologia Aplicada ao Ensino Superior (I CONTECE). Naquela ocasião, um grupo de professores da Universidade de São Paulo (USP) pôs em funcionamento um terminal, no Rio de Janeiro, acoplado por um modem nacional, por telefone, a um computador localizado no campus da USP, em São Paulo (Souza, 1983).

Nesse mesmo período, várias instituições de ensino superior passaram a realizar experimentos e simulações com o uso de computadores, iniciando assim uma nova etapa para a Educação Brasileira. Em decorrência dessas iniciativas, diversos sistemas foram desenvolvidos e, além disso, o contato com pesquisadores de outros países contribuiu para que na década de 1980 já existissem numerosas iniciativas do uso de Informática na Educação. Segundo Valente (1999), essa implantação iniciou com o primeiro e segundo Seminário Nacional de Informática na Educação (SNIE), realizados em 1981 e 1982, respectivamente. Esses acontecimentos permitiram a criação de programas governamentais, como a CAPRE (Comissão Coordenadora das Atividades de Processamento Eletrônico), a DIGIBRÁS (Empresa Digital Brasileira) e a própria SEI (Secretaria Especial de Informática), criada para regulamentar, supervisionar e fomentar a transição tecnológica do setor (Moraes, 1993).

Mais tarde, no ano de 1997, foi implantado o Programa Nacional de Informática na Educação (ProInfo), que até o final do ano de 1998 implementou 119 Núcleos de Tecnologia Educacional (NTE) em 26 Estados e no Distrito Federal e capacitou, por intermédio de cursos de especialização em Informática em Educação (360 horas), cerca de 1.419 multiplicadores para atuarem nos NTE (Valente, 1999). 
Eventos como o SBIE (Simpósio Brasileiro de Informática na Educação) e o WIE (Workshop de Informática na Escola), iniciados em 1990 e 1995, respectivamente, promovidos pela CE-IE (Comissão Especial de Informática na Educação) da Sociedade Brasileira de Computação, foram criados especificamente para publicação e apresentação de trabalhos de pesquisas cujo foco esteja no uso de tecnologias digitais, porém, não se restringindo à Educação e ao Ensino. Além desses, outros eventos com características mais específicas, como os de Educação Matemática, passaram a disponibilizar trilhas e/ou tópicos de interesse relacionados ao uso dessas ferramentas, como meio de disseminação das pesquisas realizadas nessa temática. Como exemplos de eventos nacionais e internacionais voltados a pesquisas em Educação Matemática que passaram a publicar artigos relacionados ao uso das TDIC em seus Anais temos o CIAEM (Conferência Interamericana de Educação Matemática) iniciado em 1961, o ENEM (Encontro Nacional de Educação Matemática) iniciado em 1987, o SIPEM (Seminário Internacional de Pesquisas em Educação Matemática) iniciado em 2001, e o SIPEMAT (Simpósio Internacional de Pesquisa em Educação Matemática) iniciado em 2006, dentre outros.

Embora não tenham sido criados especificamente para aceitarem artigos sobre as TDIC, ao abrirem suas portas para esse eixo temático, os eventos passaram a permitir que essas tecnologias voltadas ao ensino, especificamente o de Matemática, ganhassem maior visibilidade, mostrando à sociedade as descobertas na área e criando um campo novo de pesquisa, na fronteira do ensino de Matemática e das tecnologias. Nesse sentido, optou-se neste artigo por analisar as comunicações científicas, os relatos de experiência e pôsteres publicados nos Anais do ENEM, sendo este um dos eventos mais antigos e mais relevantes da comunidade brasileira de Educação Matemática, e, portanto, torna-se um importante lócus que congrega o uso da tecnologias, tanto de um ponto de vista histórico, quanto epistemológico, ou seja, como a sinergia entre Educação Matemática e Tecnologias Digitais vêm sendo refletida, pensada, produzida e disseminada.

Nesse sentido, vale destacar que mesmo o ENEM sendo iniciado em 1987, apenas em sua segunda edição, realizada no ano de 1988, ocorreu o primeiro registro de trabalhos relacionados ao uso das TDIC voltados à Educação Matemática. Com o passar dos anos, e de suas edições, o evento recebeu mais visibilidade e importância no meio acadêmicocientífico, o que contribui à disseminação das pesquisas e práticas nele apresentadas. Além disso, com a crescente visibilidade das pesquisas, diversos aplicativos voltados ao ensino de Matemática foram desenvolvidos, além do reconhecimento e utilização de diversos software 
internacionais, como Cabri-Geometry ${ }^{2}$, WinPlot ${ }^{3}$, GeoGebra $^{4}$, Maple $^{5}$ e Geoplan ${ }^{6}$. Frente ao exposto, e tomando como objeto as pesquisas que versam sobre o uso das TDIC em trabalhos publicados no ENEM, é necessário expor a metodologia de pesquisa.

\section{Percurso Metodológico de Pesquisa}

Depois da definição do objeto de pesquisa que são as mudanças históricoepistemológicas do uso de tecnologias, por meio de trabalhos publicados no ENEM, passouse à eleição das edições a serem analisadas, de tal modo que dado objeto em questão, considerou pertinente analisar todo o material disponível, até 2016. A escolha por analisar as 12 primeiras edições do evento vai ao encontro do que afirma a teoria fleckiana, na qual "uma das suas principais características é recorrer ao estudo histórico do conceito científico" (Klüber, 2009, p. 226). Dito de outro modo, concebe-se que no decurso histórico é possível compreender os traços que marcaram "gerações de pesquisadores e de teorias", clareando aspectos do estilo de pensamento das pesquisas sobre Tecnologias na Educação Matemática, como os seus principais modos de fazer, os seus principais autores, crenças básicas compartilhadas pelos membros do coletivo, etc. Ao lado deste aspecto epistemológico, levou-se em conta a visibilidade do evento, que é considerado hoje o maior evento de Educação Matemática do país, e por esse motivo, atrai pesquisadores de todas as regiões brasileiras, permitindo olhar de maneira abrangente sobre os diferentes modos de produção das pesquisas sobre TDIC na Educação Matemática, bem como permitem vislumbrar mudanças desde as suas primeiras edições.

O levantamento dos trabalhos ocorreu de maneira manual e sem o uso de palavraschave ou ferramentas de busca, isso devido a não haver um layout padrão nos Anais do evento, o que impossibilitou a adoção de um método de levantamento de dados mais rápido e automatizado. Diante do exposto, nossa metodologia ocorreu por meio da leitura de todos os títulos dos trabalhos publicados, e caso um título remetesse ao uso de TDIC, este era separado para futura leitura.

Ressaltamos, porém, que até a $6^{\mathrm{a}}$ edição do evento os Anais estão digitalizados em documento único, no formato PDF. A partir da $7^{a}$ edição estão disponibilizados em diferentes

\footnotetext{
${ }^{2}$ Download disponível em: http://download.cabri.com/data/cabri2plus/140/install-cabri2plus-140-pt.exe.

${ }^{3}$ Download disponível em: https://winplot.br.softonic.com/.

${ }^{4}$ Download disponível em: https://www.geogebra.org/download?lang=pt.

${ }^{5}$ Download disponível em: https://maple-17.br.softonic.com/.

${ }^{6}$ Download disponível em: http://www2.mat.ufrgs.br/edumatec/downloads/softwares/geopzip.exe.
} 
plataformas online, o que permite o download dos artigos, relatos e pôsteres em arquivos individuais. Entretanto, mesmo nas edições em que os trabalhos estão disponibilizados em arquivos individuais, a seleção ocorreu por meio da leitura dos títulos e, em alguns casos, por uma primeira leitura dos resumos, devido à possibilidade de exclusão de trabalhos ao se utilizar palavras-chave na busca, pois muitos trabalhos que relatam o uso de TDIC apresentam em seu título o nome de algum software ou algum outro termo que poderia não ser utilizado por nós no levantamento realizado, fazendo com que alguns trabalhos pudessem não ser considerados. Após esse levantamento, foram encontrados 421 trabalhos (artigos, relatos de experiência e pôsteres) nas doze edições, conforme apresentado no Quadro 1.

Quadro 1: Quantidade de trabalhos relacionados ao uso das TDIC por edição do ENEM

\begin{tabular}{|c|c|c|}
\hline Edição & Ano & Trabalhos sobre TDIC \\
\hline $\mathbf{1}^{\mathbf{a}}$ & 1987 & 0 \\
\hline $\mathbf{2}^{\mathbf{a}}$ & 1988 & 1 \\
\hline $\mathbf{3}^{\mathbf{a}}$ & 1990 & 9 \\
\hline $\mathbf{4}^{\mathbf{a}}$ & 1992 & 2 \\
\hline $\mathbf{5}^{\mathbf{a}}$ & 1995 & 13 \\
\hline $\mathbf{6}^{\mathbf{a}}$ & 1998 & 40 \\
\hline $\mathbf{7}^{\mathbf{a}}$ & 2001 & 16 \\
\hline $\mathbf{8}^{\mathbf{a}}$ & 2004 & 19 \\
\hline $\mathbf{9}^{\mathbf{a}}$ & 2007 & 61 \\
\hline $\mathbf{1 0}^{\mathbf{a}}$ & 2010 & 90 \\
\hline $\mathbf{1 1}^{\mathbf{a}}$ & 2013 & 97 \\
\hline $\mathbf{1 2}^{\mathbf{a}}$ & 2016 & 73 \\
\hline Total de trabalhos: & 421 \\
\hline
\end{tabular}

Após o levantamento de todos os trabalhos, iniciou-se a fase de leitura dos manuscritos. Para catalogar as informações encontradas optou-se por adotar a metodologia utilizada por Barbosa et al. (2019), que para sistematizar os trabalhos selecionados, criaram uma planilha eletrônica para o fichamento dos dados. Nessa planilha, os autores colocaram informações relativas ao "título, autor, filiação, número de autores, instituição de origem, modalidade da pesquisa (institucional ou interinstitucional), edição do evento, palavras-chave, resumo, nível de ensino, sujeito, enfoque temático, referencial teórico, metodologia, além dos conteúdos de estatística e probabilidade retratados nos trabalhos" (Barbosa et al., 2019, p. 324).

Desse modo, ao realizar a leitura de cada trabalho, esses dados eram fichados para futura análise. Ressalta-se, porém, que até a $6^{\text {a }}$ edição apenas os resumos estavam disponíveis, e que somente a partir da $7^{\text {a }}$ edição tivemos acesso aos trabalhos completos. Desse modo, nossa análise iniciou pela leitura dos resumos de todos os trabalhos publicados até a $6^{\text {a }}$ edição, e da leitura completa dos artigos publicados após a $7^{\mathrm{a}}$ edição, leituras essas que nos permitiram compreender as mudanças ocorridas nas pesquisas publicadas no 
ENEM, identificando preocupações distintas por período de publicação, e, também, pontos em comum entre pesquisas de diferentes edições, além de possibilitar identificar as regiões com maior participação no evento, como apresentamos a seguir.

\section{Dos resultados}

Nossa análise abordou tanto os aspectos quantitativos quanto qualitativos, e dessa forma, pudemos gerar dados comparativos entre a quantidade de trabalhos referentes ao uso das TDIC em relação à quantidade de trabalhos publicados no evento, como apresentado no Quadro 2, para posterior interpretação. Esse quadro nos revela que a quantidade de trabalhos que se referem explicitamente às tecnologias digitais não é tão elevada, contudo, dos trabalhos que foram contemplados em nossa pesquisa, o percentual está longe de ser desprezível, uma vez que há pelo menos 65 linhas de pesquisa específicas no evento. Além disso, pode-se observar, tanto no Quadro 1 quanto no Quadro 2, que a quantidade de trabalhos relacionados ao uso das TDIC aumentou edição após edição, tendo baixas somente na $4^{\mathrm{a}}, 7^{\mathrm{a}}$ e $12^{\mathrm{a}}$ edições. Entretanto, vale ressaltar que nas edições com queda no número de trabalhos sobre as TDIC, houve também uma diminuição considerável na quantidade total de trabalhos aprovados, conforme observa-se no Quadro 2, o que de certo modo, justifica tais reduções.

Quadro 2: Publicações sobre TDIC em relação ao total de trabalhos por edição do ENEM

\begin{tabular}{|c|c|c|c|c|}
\hline Edição & Ano & $\begin{array}{c}\text { Trabalhos sobre as } \\
\text { TDIC }\end{array}$ & $\begin{array}{c}\text { Total de trabalhos } \\
\text { por edição }\end{array}$ & $\begin{array}{c}\text { Porcentagem de trabalhos } \\
\text { sobre TDIC }\end{array}$ \\
\hline $\mathbf{1}^{\mathbf{a}}$ & 1987 & 0 & 11 & $0 \%$ \\
\hline $\mathbf{2}^{\mathbf{a}}$ & 1988 & 1 & 93 & $1 \%$ \\
\hline $\mathbf{3}^{\mathbf{a}}$ & 1990 & 9 & 90 & $10 \%$ \\
\hline $\mathbf{4}^{\mathbf{a}}$ & 1992 & 2 & 61 & $3 \%$ \\
\hline $\mathbf{5}^{\mathbf{a}}$ & 1995 & 13 & 180 & $7 \%$ \\
\hline $\mathbf{6}^{\mathbf{a}}$ & 1998 & 40 & 371 & $12 \%$ \\
\hline $\mathbf{7}^{\mathbf{a}}$ & 2001 & 16 & 133 & $7 \%$ \\
\hline $\mathbf{8}^{\mathbf{a}}$ & 2004 & 19 & 285 & $11 \%$ \\
\hline $\mathbf{9}^{\mathbf{a}}$ & 2007 & 61 & 554 & $9 \%$ \\
\hline $\mathbf{1 0}^{\mathbf{a}}$ & 2010 & 90 & 1031 & $6 \%$ \\
\hline $\mathbf{1 1}^{\mathbf{a}}$ & 2013 & 97 & 1505 & $5 \%$ \\
\hline $\mathbf{1 2}^{\mathbf{a}}$ & 2016 & 73 & 1434 & $7 \%$ \\
\hline & & 421 & 5748 & \\
\hline
\end{tabular}

Fonte: Os autores (2020) 
Desse modo, podemos observar que com o passar dos anos, a quantidade de pesquisadores que buscam investigar sobre o tema aumentou consideravelmente. A Figura 1 traz uma nuvem de palavras referente às palavras-chave mais utilizadas nos trabalhos publicados nas edições do ENEM analisadas, a fim de que possamos identificar, ainda que de maneira inicial e visual, o que as pesquisas publicadas no evento buscaram apresentar.

Figura 1: Nuvem de palavras-chave de artigos sobre TDIC no ENEM

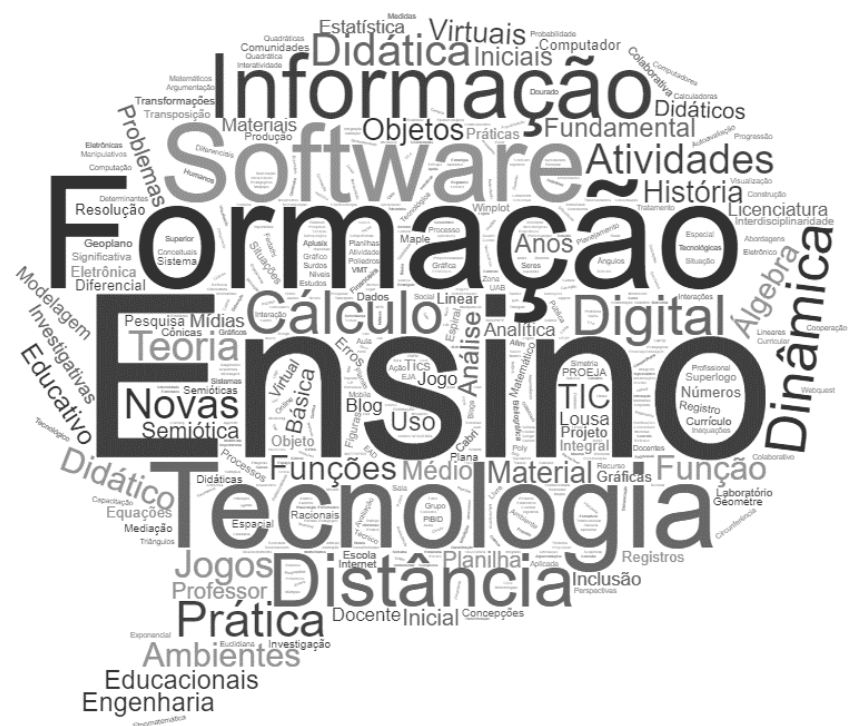

Fonte: Imagem criada com o software wordclouds (2020)

Conforme a Figura 1, é possível afirmar que as principais palavras-chave utilizadas nos 421 trabalhos selecionados foram, de maneira decrescente: Ensino, Formação, Software, Tecnologia e Informação. Ao realizar a leitura de todos os trabalhos pode-se notar que as palavras-chave citadas retratam o contexto da pesquisa de grande parte dos trabalhos apresentados, visto que todos remetem ao uso das TDIC para o ensino de Matemática por meio de software ou Internet, buscando, em alguns trabalhos, apresentar formas de capacitar os docentes para fazer uso desses recursos ou até mesmo, utilizando esses recursos tecnológicos como mediadores à formação inicial e continuada de docentes de Matemática.

Desse modo, perpassando pelas doze edições do ENEM, selecionamos textos e destacamos os principais focos, retratando o cenário da pesquisa nele publicada até o momento. Além disso, ao final da análise das doze edições, expomos diferenças entre as primeiras edições e as seguintes, a fim de identificar as mudanças ocorridas ao longo dos anos.

\section{Da análise e dos resultados}

Como já explicitado, a primeira edição do ENEM ocorreu em 1987. Nessa edição não houve publicações de trabalhos como comunicações científicas, relatos de experiência 
ou pôsteres que versassem sobre o uso das TDIC para o ensino de Matemática. Essa ausência pode demarcar, historicamente, a baixa circulação de práticas com o uso de tecnologias no campo da Educação Matemática, uma vez que o contexto ainda favorecia fortemente o uso de materiais manipulativos, materiais concretos, e sem estudos mais rigorosos em outras áreas, ou menos de difícil acesso ao campo educacional, o que mostra que o tema era ainda emergente, pois na edição subsequente, aparece um único trabalho sobre o uso das TDIC voltadas ao ensino de Matemática, intitulado: A informática no Ensino da Matemática: uma questão em discussão. O autor Araújo (1988) realizou uma pesquisa exploratória com alunos do $1^{\circ}$ e $2^{\circ}$ graus (atualmente Ensino Fundamental II e Ensino Médio, respectivamente) e com professores, buscando investigar suas percepções acerca o uso de tecnologias digitais para o ensino de Matemática, do uso de computadores e visões sobre Informática e o futuro do Brasil, por meio de uma entrevista semiestruturada.

Devido ao acesso somente ao resumo desse trabalho, não foi possível saber os resultados obtidos, somente podemos observar que a principal preocupação foi referente a como os professores e alunos estavam recebendo essas tecnologias, e quais suas opiniões acerca do assunto, que aparentemente estava começando a ter reconhecimento nas escolas. Contudo, o título é sugestivo do estágio embrionário da inserção de tecnologias no contexto da Educação Matemática Brasileira.

Já na terceira edição, cerca de dois anos depois, o número de trabalhos sobre o tema aumentou expressivamente, sendo encontrados 9 trabalhos publicados. Além disso, essa foi a primeira edição do ENEM a apresentar um núcleo temático (linha de pesquisa) destinado ao uso de tecnologias digitais, intitulado Informática no Ensino da Matemática, o que revela que a temática se torna um aspecto que, apesar do estágio inicial, passa a compor o rol ou a pauta permanente da pesquisa na área. Nessa edição, todos os trabalhos foram publicados como comunicações científicas, e a preocupação dos autores girou em torno de apresentar formas de utilização de ferramentas digitais para o ensino de Matemática, seja no trabalho de Souza et al. (1990) em que buscaram apresentar o microcomputador como uma ferramenta de trabalho, ou como no trabalho do professor Damasceno (1990) que buscou apresentar as vantagens do computador para a criação de gráficos. Os trabalhos buscavam apontar formas de aplicação, criação de software e outros meios de integrar as TDIC ao ensino de Matemática, visto que esses recursos estavam sendo inseridos nas escolas e nas vidas dos estudantes, dia após dia. Esses focos corroboram com a ideia de que o tema passa 
a ser aceito e requer discussão e experimentação, bem como a necessidade de desenvolver tecnologias específicas para o ensino de Matemática.

Na quarta edição do evento houve uma queda no número de publicações, havendo a constatação de apenas 2 trabalhos relacionados ao uso das TIDC, sendo eles uma comunicação científica e um relato de experiência. Na comunicação científica, Silva (1992) buscava apresentar novas metodologias para inserir o uso de tecnologias digitais nas aulas de Matemática, sem ignorar as consequências econômicas, políticas e sociais da época. Já no relato escrito por Carpinteiro et al. (1992) as autoras planejaram, desenvolveram e aplicaram um software educacional, o qual elas não especificam no resumo disponibilizado, mas que foi destinado aos alunos do $2^{\circ}$ grau (atual Ensino Médio) e constataram maior integração dos professores com novas tecnologias. Apesar do número reduzido de trabalhos, já indicou a presença de software educacional, o que mostra a velocidade com a qual as tecnologias alteraram seu impacto nas pesquisas em Educação Matemática, bem como, a pequena adesão nacional de professores e pesquisadores interessados no assunto, naquele momento.

$\mathrm{Na}$ quinta edição, assim como na imediatamente anterior, os pesquisadores continuaram a se preocupar com formas de integrar as TDIC ao ensino de Matemática, seja buscando metodologias para essa integração, ou realizando trabalhos diretamente nas escolas, e apresentando esses resultados no evento. Cada autor buscou, por caminhos diferentes, fazer com que o uso das TDIC fosse considerado para o Ensino. Nessa edição o número de trabalhos publicados sobre o tema aumentou para 13, com a seguinte distribuição: 4 comunicações científicas, 8 relatos de experiência e 1 pôster. Aqui, embora tenha havido uma diversidade maior nos tipos de trabalhos enviados, todos os autores buscaram apresentar formas de utilizar diferentes programas para o ensino de algum conteúdo de matemática, ou então, relatar experiências em que utilizaram tecnologias digitais com alunos, de forma a apresentar as vantagens que esses recursos podem oferecer ao ensino de Matemática. O nível exploratório das pesquisas continua a indicar um momento de instauração de um subcampo de pesquisa, pois as experiências são individuais e centradas em casos, sem o aporte de projetos mais amplos e com durabilidade média indicada.

Quanto à sexta edição, realizada no ano de 1998, o número de trabalhos aprovados superou em quantidade os trabalhos enviados nas últimas cinco edições do ENEM, e isso ocorreu, em grande parte, graças à popularização da Internet para interesses acadêmicos, conforme afirmam Carvalho et al. (1999). Nesta edição foram publicadas 30 comunicações científicas e 10 pôsteres, totalizando 40 trabalhos acerca de TDIC. Além de, até o momento, 
ser a edição com maior quantidade de trabalhos publicados, percebe-se mudanças no foco das pesquisas publicadas, se comparado às 5 primeiras edições. Nela, aparecem os primeiros relatos referentes ao uso da internet como mediadora na Educação a Distância (EaD), como no trabalho escrito por Peixoto e Notare (1998), no qual desenvolveram e implementaram na Internet um curso a distância sobre funções, buscando auxiliar os professores no ensino de conteúdos matemáticos do $2^{\circ}$ grau (atual Ensino Médio).

Outro ponto muito forte nessa edição é o uso de sistemas como Maple, Logo e Derive para o ensino de derivadas, gráficos de funções e geometria. Entretanto, o software CabriGéomètre foi o que mais se destacou nesta edição, sendo o mais citado pelos autores e, em todos os casos, como um suporte visual à compreensão de conteúdos e figuras geométricas. Podemos observar que nesta edição houve um aumento nos trabalhos que visavam mostrar as vantagens proporcionadas pelo uso de software para o ensino, em especial, de Geometria, assim como a aparição de um primeiro trabalho sobre como utilizar a EaD por meio da Internet. Como vínhamos discorrendo, foram desenvolvidos ou popularizados novos software para o ensino de Matemática, além da popularização dos "ambientes virtuais" como chats e fóruns. Essa mudança pode indicar uma virada paradigmática que contempla dois movimentos, um que decorre das mudanças das tecnologias digitais e outro que decorre do desenvolvimento de software específicos. Essa guinada possui duas facetas: o abandono sem o devido aprofundamento das tecnologias até então exploradas e a necessidade de uma nova "corrida" para acompanhar as rápidas mudanças tecnológicas. Essa afirmação é consistente com os dados analisados, mas merece uma investigação mais profunda.

A partir da sétima edição os Anais do ENEM passaram a ser disponibilizados de forma diferente das anteriores, em uma plataforma online, em arquivos individuais, o que nos permitiu observar que com o desenvolvimento da tecnologia, e a expansão da Internet tornou-se possível disponibilizar os trabalhos de forma a facilitar o seu acesso, pois nessa edição, para selecionar um trabalho para leitura, basta o leitor ler o título, que é apresentado em ordem alfabética, e caso tenha interesse, baixar o arquivo do artigo em uma das opções disponíveis na mesma linha em que se encontra seu título, o que permite ter, ainda que de forma simplista, uma ideia das mudanças ocorridas entre os anos de 1998 e de 2001, e que barateamento dos equipamentos, aumento da capacidade de armazenamento e pela Internet, tornou mais fácil a disponibilização e o acesso à informação.

Entretanto, mesmo com as mudanças e o desenvolvimento da Internet, nesta edição o número de pesquisas que remeteram ao uso de tecnologias digitais publicadas ao ENEM 
caiu, se comparado com a edição imediatamente anterior. Houve o registro de apenas 16 trabalhos publicados, sendo 10 comunicações científicas e 6 relatos de experiência. Conforme observa-se no Quadro 1 e Quadro 2, o número de trabalhos enviados ao evento no ano de 2001 foi aproximadamente 2,7 vezes menor que a quantidade de trabalhos enviados no ano de 1998, e isso se dá em relação ao paradigma predominante nas TDIC em âmbito tecnológico e Educacional. Como o foco não era mais o uso de software, mas o uso da internet e os desafios daí decorrentes, é razoável pensar que os pesquisadores passaram, em três anos, por um processo de migração das ferramentas, o que consequentemente reduziu a quantidade de resultados de pesquisas enviados para essa edição. Sendo assim, é plausível admitir que surgiram novas comunidades buscando dar conta destes novos aspectos. Esse é outro aspecto que merece uma nova investigação. Porém, a não continuidade em termos quantitativos indica rotatividade dos pesquisadores que participam do evento, além de, mesmo o evento sendo nacional, a participação local incidir diretamente sobre as temáticas, merecendo assim atenção sobre essa rotatividade e articulação nacional.

Esta edição, pela leitura dos artigos disponibilizados na íntegra, permitiu uma compreensão em maior profundidade. Desse modo, pudemos compreender que os autores continuaram a se preocupar com maneiras de integrar as TDIC nas aulas de Matemática, porém, pode-se observar novas formas de integração dessas tecnologias, como no trabalho de Brolezzi (2001) que relatou como a Internet pode ser utilizada para acesso de conteúdos históricos, de maneira mais rápida e simples que pesquisas em livros, porém, sem desmerecimento desses meios. O autor retratou uma experiência ao usar história e tecnologia para o ensino de Matemática, concluindo que:

As tecnologias de informação, que estão modelando novas concepções de ensino e aprendizagem e até mesmo diferentes concepções de inteligência, parecem constituir elemento importante, se não fundamental, para que o uso da História da Matemática passe a influenciar de forma significativa a prática docente. (Brolezzi, 2001, p. 5)

Além disso, em outro trabalho apresentado nesta edição, escrito por Silva e Souza Junior (2001) pode-se perceber os primeiros sinais em que os autores passaram a considerar que com o uso das tecnologias digitais os alunos podem compreender melhor o conteúdo de modo a produzirem "seus próprios conhecimentos" (p. 1). Passou-se então, da simples inserção e indução do uso de tecnologias digitais, para a comunicação ou às relações que podem ser mediadas pela tecnologia digital, ou seja, de forma a mudar a relação entre 
professor, aluno e tecnologia, indicando, assim, uma possível inflexão ou mudança de paradigma $^{7}$, ainda que o anterior continue, simultaneamente.

Na edição seguinte, que ocorreu no ano de 2004, foram publicados 19 trabalhos que versavam sobre o uso das TDIC. Destes, 15 foram como comunicações científicas, 2 como relatos de experiência e 2 como pôsteres. A partir dessa oitava edição, o número de trabalhos relacionados ao uso das tecnologias digitais passou a aumentar, o que se deve, em grande parte, aos avanços tecnológicos, a exemplo do surgimento de dispositivos móveis ocorridos nesse período.

Assim como nas primeiras sete edições, nessa podemos notar a preocupação dos pesquisadores em inserir as TDIC no contexto escolar, entretanto, esta preocupação não se deu somente em mostrar formas de utilizar, quando utilizar e quais ferramentas utilizar, mas sim em apresentar exemplos de trabalhos desenvolvidos em sala de aula ou em laboratório de Informática das escolas, a fim de mostrar as vantagens desses recursos por meio de situações reais, vivenciadas pelos autores, levando o leitor a refletir sobre a possível aplicação dessas atividades em suas aulas. Na leitura dos trabalhos constatamos que embora com objetivos distintos, quase todos os trabalhos desta edição possuem uma estrutura semelhante, na qual os autores, após apresentação de seu referencial teórico, introduzem algum tipo de tecnologia digital (software, jogo, ou recurso online) que pode ser utilizada nas aulas de Matemática, notando a preocupação dos autores em descrever de forma detalhada as etapas de pesquisa para que possam ser reproduzidas por outros profissionais.

No entanto, alguns trabalhos fogem a essa ideia, como o de Andrade e Nacarato (2004) que traz uma revisão buscando identificar quais tendências se faziam presentes no ensino de Geometria naquele período. Para isso, optaram por analisar os Anais das sete primeiras edições do ENEM, a fim de identificar quais software eram utilizados, de que forma faziam uso desses recursos, e quais os principais conteúdos abordados para o ensino de Geometria. Esse trabalho mostrou que já havia uma percepção dos pesquisadores sobre a presença de software educacionais no evento. Esse tipo de movimento "meta-analítico" mostra, de certo modo, uma necessidade de autoconhecimento da área e dá indícios de que é necessário passar à outras temáticas e fases de pesquisa.

\footnotetext{
${ }^{7}$ Entende-se por mudança de paradigma a alteração no modo de foco das pesquisas até a sexta edição, que visavam investigar e apresentar formas de utilizar as TDIC, para pesquisas que vão além, e buscam entender a relação entre professor-tecnologia-aluno e as inferências dessas ferramentas no ensino de Matemática.
} 
Na nona edição, ocorrida em 2007, foram publicados 61 trabalhos acerca das TDIC, divididos em 30 comunicações científicas, 22 relatos de experiência e 9 pôsteres. Percebese nessa edição a forte preocupação dos pesquisadores com a capacitação docente para o uso das TDIC, na qual apontam a necessidade de inclusão de disciplinas na educação inicial que permitam a preparação e capacitação desses novos docentes para trabalhar pedagogicamente com as tecnologias digitais, além de cursos de formação continuada que permitam constante aprimoramento dos docentes. Com essas pesquisas, voltadas à formação inicial e continuada, os pesquisadores apresentam lacunas no processo de formação docente, que deveria fornecer subsídios para uma melhor preparação do professor.

Além disso, nota-se nesta edição, um crescente uso das tecnologias digitais na EaD, seja como ambiente online de ensino mais amplo, ou como recurso pedagógico para o estudo de conteúdos específicos, como o exemplo da Geometria, apresentando as vantagens proporcionadas por esses ambientes virtuais, como o acesso remoto ao mesmo material de ensino. Ainda, nessa edição, alguns pesquisadores discutiram sobre as diferentes visões que o ambiente escolar tem sobre as TDIC, desde o aluno, passando pelo professor até a coordenação escolar, as quais, segundo alguns pesquisadores, nem sempre contribuem para a implementação e utilização de recursos tecnológicos.

Outro ponto a ressaltar é o fato de que as pesquisas que remetem a formas de utilização das TDIC, elaboração e implementação de atividades, tiveram menor número de publicações, fato que vem se evidenciando desde a sétima edição, e concentraram-se, quase que totalmente, em relatos de experiência. Observamos que a preocupação dos pesquisadores nesse período não está focada a apresentar formas de utilizar essas tecnologias, ou relatar suas experiências com o uso de tais recursos, mas sim de apresentar dados que comprovem a necessidade dessa utilização, seus benefícios, e as dificuldades existentes na integração dessas ferramentas nas aulas de Matemática, independentemente do nível de ensino. Chamamos isso de novo ciclo de teorização, portanto, um indício histórico-epistemológico dos aspectos que interessam à comunidade, no qual os pesquisadores mudaram seus focos de pesquisa, o que nos permite inferir o início de um novo ciclo de pesquisas acerca do uso das TDIC, porém, agora com outros pesquisadores e professores que dispõem de um amplo acervo de materiais teóricos, além de novos recursos tecnológicos, podendo embasar-se em erros e acertos de pesquisas mais antigas, e se adaptar mais facilmente às novas tecnologias.

Essa preocupação dos docentes pode ser observada também na décima edição do evento, a qual ocorreu em 2010, e publicou 90 trabalhos sobre TDIC. Destes, 30 foram 
comunicações científicas, 34 foram relatos de experiência e 26 são pôsteres. Ainda, nessa edição, os trabalhos foram divididos em dois eixos de pesquisa: Educação a Distância e Recursos e Processos Tecnológicos. O primeiro, Educação a Distância, foi composto por 10 comunicações científicas e 9 relatos de experiência. Nesses trabalhos, pudemos observar a predominância de pesquisas que apresentam benefícios, principalmente, na utilização de Ambientes Virtuais de Ensino e Aprendizagem (AVEA), bem como algumas dificuldades oriundas do processo de formação inicial online.

Dentre os 19 trabalhos apresentados nesse tema de pesquisa, 12 apresentam discussões referentes à formação inicial e/ou continuada de professores de Matemática, abordando aspectos positivos da formação a distância com o uso de AVEA e empecilhos ligados às dificuldades de aprendizagem que podem ocorrer nesses ambientes por parte de alunos que necessitam de maior interação com o professor e com os demais colegas de classe. Além disso, foram publicados trabalhos em que os pesquisadores utilizavam AVEA, como o Moodle, como auxílio em aulas presenciais, citado por um artigo como um recurso que pode estender o ambiente de estudos dos alunos, a depender da forma como for utilizada, mostrando indícios de como incorporar a EaD na Educação Matemática.

O eixo temático Recursos e Processos Tecnológicos publicou 71 trabalhos, sendo 20 comunicações científicas, 25 relatos de experiência e 26 pôsteres. Neste, os trabalhos diversificaram-se se comparados ao anterior. Desse modo, constatamos distintos focos de pesquisa, desde trabalhos bibliográficos que visaram investigar dissertações e teses a respeito do uso das TDIC, a trabalhos que versam sobre desenvolvimento de ambientes computacionais de apoio ao aluno, aplicação de atividades com alunos do Ensino Fundamental e Médio, dentre outros. Ainda, houve trabalhos que ressaltaram a necessidade de capacitação aos docentes para que estes possam integrar as TDIC às suas aulas, mostrando suas dificuldades quanto à utilização dessas tecnologias por falta de conhecimento, e dificuldades geradas no alunado devido ao despreparo do docente.

No ano de 2013 foi realizada a décima primeira edição que contou com 97 trabalhos publicados referentes ao uso das TDIC. Esses trabalhos foram divididos entre 39 comunicações científicas, 39 relatos de experiência e 19 pôsteres. Novamente, percebeu-se a preocupação dos pesquisadores em realizar pesquisas que vão além das formas de utilização. Os autores, de modo geral, apresentaram resultados de pesquisas que fortalecem as vantagens trazidas pelo uso das TDIC ao ensino de Matemática. Nesse sentido, constatamos trabalhos em que os pesquisadores fizeram uso de conceitos da história da Matemática e de tecnologias 
digitais para ressignificar o ensino dos alunos, bem como trabalhos bibliográficos que investigaram como ocorre o uso das TDIC para o ensino de determinados conteúdos (como os de Cálculo e Geometria, por exemplo), além de trabalhos, que assim como em edições anteriores, preocuparam-se com a formação inicial e continuada dos docentes.

Podemos perceber que entre a décima e a décima primeira edições, os trabalhos mantiveram-se na mesma ideia principal, a de apresentar pesquisas que além de relatar experiências em sala de aula ou com a utilização de determinadas ferramentas, preocuparamse com outros aspectos, como a capacitação docente para utilização desses recursos, meios de utilização dessas ferramentas, diferentes abordagens em diferentes software, todos com o propósito tanto de apresentar as vantagens proporcionalizadas por essas ferramentas quanto ao seu uso pedagógico para o ensino de Matemática. Essa preocupação dos autores, do ponto de vista da teoria fleckiana, mostra que após as mudanças explicitadas, os pesquisadores voltaram a convergir para um mesmo foco de pesquisa, confirmando a construção do conhecimento como algo que é regulado e chancelado coletivamente.

Essa preocupação é notada com maior força na décima segunda edição do evento, na qual um total de 22 artigos, dentre os 73 aprovados para essa edição sobre o tema ora discutido, buscaram investigar formas de integrar tecnologias digitais nos currículos das escolas, e quais os conhecimentos básicos para que professores tenham capacidade de utilizar esses recursos em sala de aula, e até mesmo, se fazem essa utilização, como no trabalho de Gomes (2016) que investigou se a formação inicial do professor que leciona Matemática tem dado suporte para que trabalhe com essas tecnologias em sala de aula, bem como visou verificar se esses docentes se sentiam seguros para utilizá-las.

Nesta edição, foram enviados 48 comunicações científicas e 25 relatos de experiência, e como mencionado, 22 trabalhos versavam sobre preocupações com a formação inicial e capacitação continuada dos docentes para que os recursos tecnológicos sejam integrados às aulas, sendo um dos principais pontos ressaltados pelos pesquisadores: a falta de preparação dos professores para tal tarefa. Além disso, tem-se o registro de trabalhos que realizaram levantamentos bibliográficos, formas de ensinar determinados conteúdos por meio de software específicos, dentre vários outros temas abordados, sendo os trabalhos que se preocupavam com a formação e preparação dos docentes os de maior quantidade nesta edição, evidenciando a necessidade de investimentos e de ofertas de capacitação para esses profissionais. 
Ao final da análise das doze edições, pode-se ter um panorama das pesquisas publicadas nos Anais do ENEM no que se refere às TDIC, e podemos afirmar que uma comunidade de pesquisadores emergiu em torno deste eixo que sofreu mudanças acentuadas em 30 anos. No Quadro 3 apresentamos um comparativo da quantidade de trabalhos enviados ao evento em suas primeiras doze edições, separadas por tipo de publicação analisada, e identificados da seguinte maneira: Comunicação Científica (CC), Relato de Experiência (RE) e Pôster (P), no qual separa-se os trabalhos relacionados ao uso das TDIC dos demais trabalhos publicados.

A partir do Quadro 3, podemos constatar a quantidade de trabalhos enviados em cada modalidade de pesquisa. Ao longo das doze (12) edições do ENEM, realizadas entre os anos de 1987 a 2016, foram aceitos e publicados 5.744 (cinco mil setecentos e quarenta e quatro) trabalhos, sendo 421 (aproximadamente 7,33\%) referentes ao uso de tecnologias digitais. Desses, 217 foram enviados como comunicações científicas, 137 como relatos de experiência e 67 como pôsteres. Se comparado com a coluna "Trabalhos não relacionados às Tecnologias Digitais" é considerável a diferença, ficando visível, aparentemente, que outros temas receberam maiores registros no evento. Um possível motivo para que isso tenha ocorrido nas primeiras edições, refere-se ao período histórico-social em que foram realizadas as edições, visto que tais tecnologias voltadas ao ensino, em especial o de Matemática, ainda estavam em descoberta ou experimentação, o que justifica a baixa quantidade de trabalhos nesse período.

Quadro 3: Comparativo dos tipos de trabalho enviados ao ENEM por edição

\begin{tabular}{|c|c|c|c|c|c|c|c|c|c|c|}
\hline \multirow{2}{*}{ Edição } & \multirow{2}{*}{ Ano } & \multicolumn{4}{|c|}{$\begin{array}{c}\text { Trabalhos sobre Tecnologias } \\
\text { Digitais }\end{array}$} & \multicolumn{4}{|c|}{$\begin{array}{c}\text { Trabalhos não relacionados às } \\
\text { Tecnologias Digitais }\end{array}$} & \multirow{2}{*}{$\begin{array}{c}\text { Total de } \\
\text { trabalhos } \\
\text { por edição }\end{array}$} \\
\hline & & $\mathrm{CC}$ & $\mathrm{RE}$ & $\mathrm{P}$ & Total & $\mathrm{CC}$ & $\mathrm{RE}$ & $\mathrm{P}$ & Total & \\
\hline $1^{a}$ & 1987 & 0 & 0 & 0 & 0 & 11 & 0 & 0 & 11 & 11 \\
\hline $2^{\mathrm{a}}$ & 1988 & 1 & 0 & 0 & 1 & 92 & 0 & 0 & 92 & 93 \\
\hline $3^{a}$ & 1990 & 9 & 0 & 0 & 9 & 81 & 0 & 0 & 81 & 90 \\
\hline $4^{a}$ & 1992 & 1 & 1 & 0 & 2 & 32 & 27 & 0 & 59 & 61 \\
\hline $5^{a}$ & 1995 & 4 & 8 & 1 & 13 & 63 & 77 & 27 & 167 & 180 \\
\hline $6^{\mathbf{a}}$ & 1998 & 30 & 0 & 10 & 40 & 257 & 0 & 74 & 331 & 371 \\
\hline $7^{a}$ & 2001 & 10 & 6 & 0 & 16 & 83 & 31 & 3 & 117 & 133 \\
\hline $8^{a}$ & 2004 & 15 & 2 & 2 & 19 & 147 & 59 & 54 & 260 & 279 \\
\hline $9^{a}$ & 2007 & 30 & 22 & 9 & 61 & 248 & 98 & 147 & 493 & 554 \\
\hline $10^{a}$ & 2010 & 30 & 34 & 26 & 90 & 511 & 288 & 144 & 943 & 1033 \\
\hline $11^{\mathrm{a}}$ & 2013 & 39 & 39 & 19 & 97 & 741 & 470 & 197 & 1408 & 1505 \\
\hline $12^{\mathrm{a}}$ & 2016 & 48 & 25 & 0 & 73 & 923 & 438 & 0 & 1361 & 1434 \\
\hline \multicolumn{2}{|c|}{ Total } & 217 & 137 & 67 & 421 & 3189 & 1488 & 646 & 5323 & 5744 \\
\hline
\end{tabular}

Fonte: Os autores (2020) 
Nas edições seguintes, ocorridas após a expansão do uso dessas tecnologias para o ensino, notamos que o evento adquiriu novos adeptos, o que aumentou a quantidade de trabalhos também em outras áreas. Dentre outras informações, como pode ser observado no gráfico da Figura 2, foi possível identificar as regiões do país com maior frequência de publicação ao longo das edições do ENEM. Para melhor representação gráfica, os estados que não tiveram registros de trabalhos relacionados ao uso de TDIC ao longo do evento não foram inseridos.

Figura 2: Regiões com maior participação de pesquisadores sobre TDIC

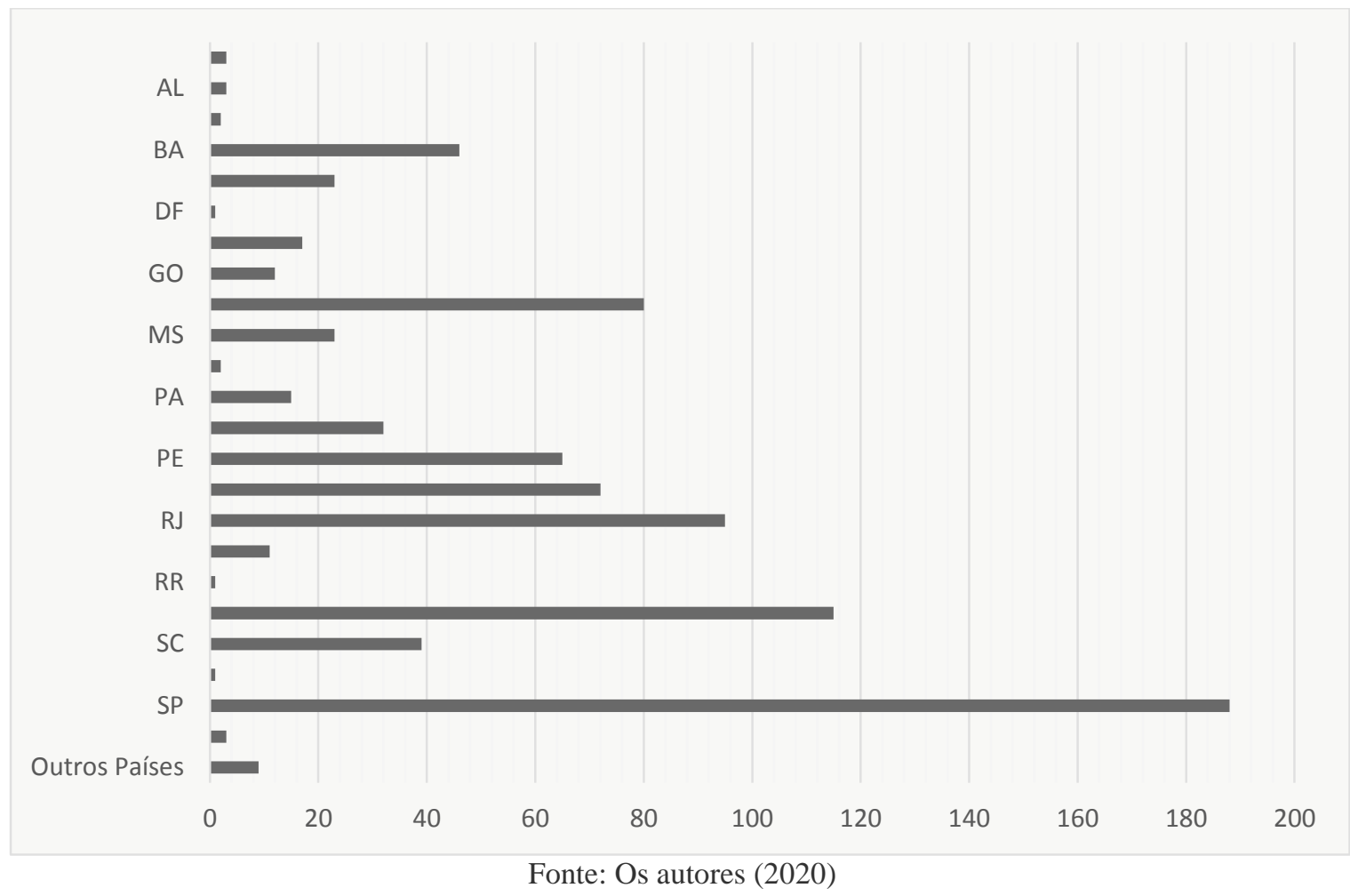

Os dados apresentados na Figura 2 foram obtidos por meio das informações constantes nos trabalhos publicados no ENEM, pois com exceção de alguns trabalhos em diferentes edições, todos continham o nome da instituição a qual o pesquisador estava vinculado no período de sua pesquisa. Ressalta-se que com o passar dos anos alguns pesquisadores mudaram de instituição, e até mesmo de estado, e por esse motivo foram consideradas as informações contidas nos trabalhos publicados, a fim de compreender como estava a distribuição geográfica das pesquisas relacionadas às tecnologias digitais em cada edição. Nos trabalhos que não constavam as instituições às quais os autores pertenciam, foram observados seus currículos Lattes, a fim de identificar a região em que atuavam no ano da publicação no evento. 
Por meio desses dados podemos observar que os três estados com maior frequência de participação foram São Paulo, Rio Grande do Sul e Rio de Janeiro, com 22\%, $13 \%$ e 11\% dos autores, respectivamente, notando a predominância de pesquisadores das regiões Sul e Sudeste no que concerne às pesquisas relacionadas às TDIC apresentadas no ENEM. Isso acontece, dentre outros fatores, por essas terem sido as regiões que tiveram os primeiros contatos com o uso de tecnologias digitais em eventos, como o I CONTECE realizado em 1971 no Rio de Janeiro, e por terem renomadas instituições de ensino superior e pioneiras em pesquisas nessa área.

Além disso, foi possível constatar a participação de pesquisadores de outros países, como França, Espanha, Estados Unidos e Paraguai. Embora todos os trabalhos devessem ser escritos em português, isso não impediu a participação de pesquisadores de outros países, muitos em colaboração com autores brasileiros, o que revela a importância e abrangência que o ENEM vem tomando, e que o uso das TDIC para o ensino de Matemática também é de interesse em outros países. Esse movimento se assenta naquilo que Fleck esclareceu sobre circulação intercoletiva de ideias (Fleck, 1986). Em outras palavras, o diálogo com pesquisadores de outros países, com tradições e visões de Matemática, educação e tecnologias, passou a compor o estilo de pensamento da pesquisa brasileira de um modo mais acentuado.

Ainda, cabe ressaltar que foram constatadas a participação nas publicações de 41 professores que atuam ou atuavam no Ensino Fundamental, Médio ou Técnico dos diversos estados brasileiros, o que nos permite ressaltar que o ENEM abre portas para professores e pesquisadores de todos os níveis de ensino, não apenas aos com vínculos com instituições de ensino superior, permitindo a socialização de conhecimentos e esclarecimento dúvidas, o que contribui com toda a comunidade acadêmica.

Foi possível também observar certas mudanças ocorridas nas edições do evento, podendo-se considerar que a preocupação das pesquisas tomou novos caminhos, havendo assim uma mudança no estilo de pensamento dos pesquisadores. Segundo Löwy (1994, p. 11) a mudança no estilo de pensamento resulta em "uma maior capacidade de reconhecer certos fenômenos e adquirir certas habilidades técnicas". Além disso, a mudança "das pressuposições anteriores permite o aparecimento de novas possibilidades de interpretação e cria fatos novos" (Fleck ${ }^{8}, 1986$, apud Delizoicov et al., 2002, p. 58). Esses profissionais deixaram de pesquisar somente formas de utilizar esses recursos tecnológicos, e passaram a

\footnotetext{
${ }^{8}$ Fleck, L. (1986). La Génesis y el Desarrollo de un Hecho Científico. Alianza Editorial.
} 
investigar formas de integrar essas ferramentas às suas salas de aula, a identificar as competências necessárias para que futuros professores possam também fazer uso dessas tecnologias em sala, e quais os efeitos - positivos ou negativos - gerados nos alunos em decorrência do uso das tecnologias digitais, além de diversas outras pesquisas que caminham nessa direção.

Após analisar os trabalhos aceitos e publicados no evento, voltados ao uso das tecnologias digitais, pode-se observar mudanças entre as primeiras edições e as seguintes no que se refere ao foco das pesquisas realizadas, as quais se modificaram nas últimas três décadas, porém, não abandonando os objetivos iniciais. Podemos dizer que ocorreram três grandes mudanças, que ainda precisam ser mais bem investigadas, no tocante aos processos histórico-epistemológicos de produção do conhecimento das tecnologias na Educação Matemática, como se pode ver na Figura 3.

Figura 3: Principais focos dos artigos em TDIC publicados no ENEM

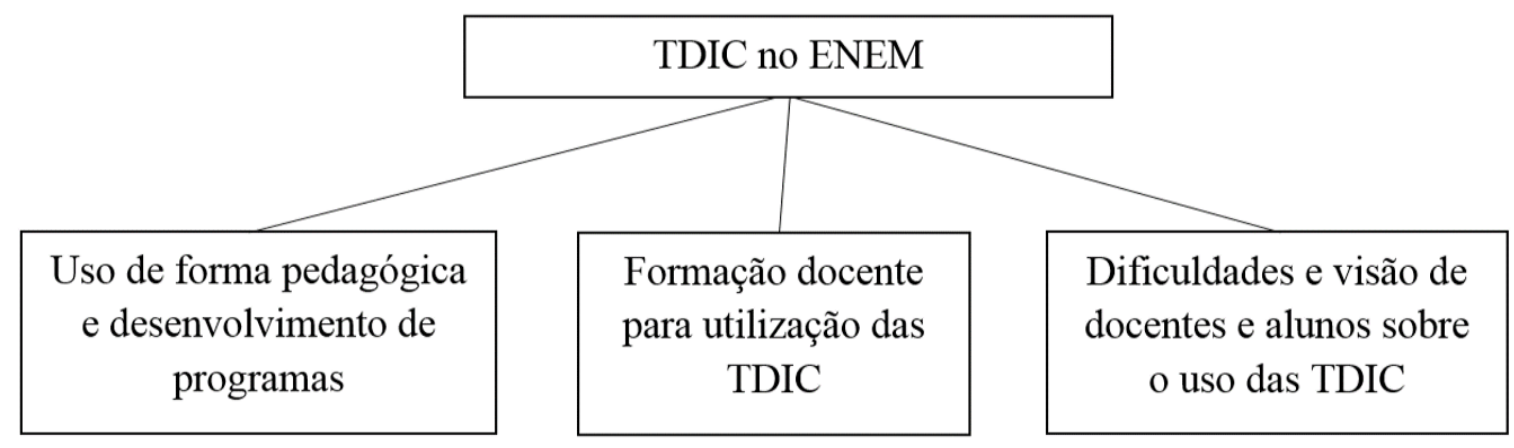

Fonte: Os autores (2020)

Num primeiro momento, observa-se nos trabalhos apresentados um maior interesse em investigar formas de utilizar pedagogicamente as TDIC para o ensino, bem como a preocupação dos pesquisadores em desenvolver programas para apoiar o estudo de conteúdos de Matemática. Em um segundo momento, nota-se uma diminuição nessas pesquisas, e uma grande quantidade de trabalhos com foco na formação docente, o que nos permite inferir que após a criação e apresentação de formas de utilizar as TDIC pedagogicamente nas escolas, tornou-se necessário capacitar os docentes para que fizessem uso dessas tecnologias em sala de aula. Em um terceiro momento, observamos que o foco das pesquisas passou a ser mais referente às dificuldades dos docentes e alunos em utilizar essas tecnologias digitais, bem como suas avaliações sobre experiências de uso.

Essas mudanças nos permitem observar que o surgimento de um novo ciclo de pesquisa se apoia em questões já discutidas pela comunidade, que abrem possibilidades para novas investigações. Ressalta-se, porém, que o surgimento de um novo foco de pesquisa não 
exclui o anterior, mas que implica na redução da quantidade de trabalhos publicados sobre o tema anterior, sendo os novos temas investigados com maior força, como uma nova tendência. Alguns motivos para essas mudanças estão diretamente relacionados à época em que as pesquisas foram realizadas, ou seja, os primeiros trabalhos são datados de 1988 a 1995, e por se tratar de um período de descobertas nessa área, sem Internet, os pesquisadores passaram a mostrar formas de utilizar as tecnologias digitais para o ensino, visto que poucas pessoas tinham contato e acesso a esses recursos nesse período.

Com o desenvolvimento acelerado dessas tecnologias, além de mostrar como utilizar tais recursos, passou a ser necessário integrar esses recursos nas escolas, bem como identificar os efeitos que o uso causa nos alunos e professores, necessitando assim de maior afinidade dos pesquisadores com essas ferramentas, o que modifica a própria visão sobre a tecnologia, que antes era algo "externo" e agora é algo "internalizado" por muitos de nós.

\section{Considerações Finais}

Com o objetivo de observar as mudanças que ocorreram nas pesquisas ao longo da história do ENEM no que se refere à Educação Matemática e Tecnologias Digitais, foi realizada a seleção e a leitura dos 421 trabalhos publicados sobre o tema ao longo das 12 primeiras edições do ENEM, que ocorreram entre os anos de 1987 a 2016, o que nos permitiu conhecer um pouco mais sobre o uso das tecnologias na Educação Matemática no Brasil, desde os primeiros recursos, uso somente em computadores, primeiros programas desenvolvidos para a área, e primeiros relatos de uso em escolas públicas, até as tecnologias mais atuais, como o uso em smartphones, tablets, ou notebooks. Foi possível também observar a maneira como os trabalhos eram realizados há mais de 30 anos, e as mudanças nos focos das pesquisas realizadas ao longo das edições, além de mudanças mais superficiais, como as normas e padrões do evento, que esteticamente foram as que sofreram mais mudanças.

Embora tenhamos observado a presença de três grandes mudanças no foco dos pesquisadores ao longo dos 30 anos do evento, deve-se atentar que o surgimento de um novo foco não exclui o anterior. Além disso, embora seja possível identificar a mudança nas pesquisas, deve-se considerar que não ocorreram de forma linear, sendo ainda possível encontrar trabalhos que versão sobre tais mudanças em todas as edições, ainda que com quantidade muito reduzida. 
Em relação às principais mudanças percebidas, podemos situar no evento onde cada uma possuiu maior força. Até a quinta edição do ENEM, pode-se observar que os trabalhos buscavam apresentar, quase que de forma unânime, formas de utilização dessas ferramentas, novos programas, e relatos de experiência de uso. A partir da sexta edição, notou-se que um grupo de pesquisadores passou a realizar pesquisas com outros focos, ficando ainda mais evidente nas edições seguintes, nas quais tem-se o registro de trabalhos que buscam investigar sobre a formação docente para utilização desses recursos, quais os reflexos do uso das TDIC nos alunos, ou trabalhos puramente bibliográficos, que visaram apresentar quais os principais software que vinham sendo utilizados, dentre outras pesquisas que não estão especificamente buscando apresentar formas de utilizar tais tecnologias, mas explorando novos ramos de pesquisa.

Essas mudanças, que de certa maneira caracterizam um movimento históricoepistemológico, podem ter ocorrido por diversos fatores, mais ou menos identificáveis coletivamente. Devemos considerar, ainda, que o momento histórico em que viviam exerceu grande influência nessas mudanças, e por esse motivo, poucos eram os que tinham afinidade com tais recursos, ou tinham acesso facilitado a tais equipamentos. $\mathrm{O}$ desenvolvimento tecnológico e o passar dos anos contribuíram para que essa dificuldade deixasse de ser um grande problema, porém, não se extinguindo, passando os pesquisadores a investigar os novos empecilhos existentes na integração dessas tecnologias no ambiente escolar, muitas vezes sem se dar conta de problemas que eram relevantes no estilo de pensamento de edições anteriores.

Esperamos que esse trabalho possibilite ao leitor uma compreensão sobre os indícios de mudanças ocorridas no foco das pesquisas realizadas ao longo dos anos, que deixaram de investigar somente as maneiras de utilizar essas tecnologias digitais, passando a preocuparse também com os efeitos e outros aspectos relacionados ao seu uso, como a formação inicial e continuada dos docentes, e as implicações do uso dessas tecnologias no desenvolvimento dos estudantes. Ainda, espera-se que o presente trabalho contribua para que os pesquisadores das diversas áreas da Educação Matemática, no que concerne à realização de investigações relacionadas ao uso das tecnologias digitais, pois conforme afirmado por Barbosa et al. (2019, p. 321) "estudos que desenvolvem mapeamento com uma abrangência específica e discorrem sobre os conhecimentos já elaborados podem apontar caminhos, tendências e lacunas nas opções dos pesquisadores”.

Como trabalhos futuros, várias nuances detectadas na pesquisa serão investigadas em profundidade para sua compreensão. Ademais, inspirados pelo interesse em compreender o 
ENEM, nos diferentes eixos temáticos, espera-se realizar trabalhos semelhantes em novos temas, a fim de identificar novos cenários e potencialidades de pesquisa na área de Educação Matemática, como Modelagem Matemática, História da Matemática, dentre outras. Ressalta-se ainda que, na elaboração de novos trabalhos, bem como na continuação do presente, buscar-se-á a reusabilidade de nosso método de investigação, criando assim um framework relacionado a como realizar pesquisas como essa em diferentes eventos científicos, nas diversas áreas de conhecimento.

\section{Referências}

Andrade, J. A. A. \& Nacarato, A. M. (2004). Atuais tendências didático-pedagógicas no ensino de geometria: Um olhar sobre os anais dos ENEM's. Em C. M. C. Pires e M. R. Castro (Eds.), Anais VIII ENEM - Encontro Nacional de Educação Matemática (pp. 113). Sociedade Brasileira de Educação Matemática (SBEM). http://bit.ly/31QWdKM.

Antunes, V. H. R. B. \& Cibotto, R. A. G. (2018). Tecnologias da Informação e Comunicação: Um Diagnóstico acerca de seu uso por docentes de Matemática. Educação Matemática em Revista - RS, 1(19), 80-92. http://bit.ly/2YBp30r.

Araújo, A. P. (1998). A informática no Ensino da Matemática: Uma questão em discussão. Em E. A. Toledo (Ed.), Anais II ENEM - Encontro Nacional de Educação Matemática (pp. 3). Sociedade Brasileira de Educação Matemática (SBEM). http://bit.ly/2naWWGX.

Barbosa, G. C., Santos, S. S. \& Lopes, C. E. (2019). Um cenário das pesquisas envolvendo educação estatística na edição do XII ENEM. Rencima: Revista de Ensino de Ciências e Matemática, 10(6), 319-339. http://bit.ly/39t9DPL.

Brolezzi, A. C. (2001). Uso de Novas Tecnologias para o estudo e o Uso da História da Matemática em Sala de Aula. Em T. M. M. Campos (Ed.), Anais VII ENEM - Encontro Nacional de Educação Matemática (pp. 1-7). Sociedade Brasileira de Educação Matemática (SBEM). http://bit.ly/2naWWGX.

Carpinteiro, M. R. S., Lopes, M. L. L., Fernandes, L. \& Bernardino, G. H. (1992). Metodologia de Planejamento e avaliação de software educacional de Matemática. Em J. V. Floriani (Ed.), Anais IV ENEM - Encontro Nacional de Educação Matemática (pp. 126). Sociedade Brasileira de Educação Matemática (SBEM). http://bit.ly/2naWWGX.

Carvalho, J. M., Arita, C. H. \& Nunes, A. F. (1999). A política de implantação da Internet no Brasil. Em Intercom (Ed.), Anais XXII Congresso Brasileiro de Ciências da Comunicação (pp. 1-15). Intercom. https://bit.ly/3a7cQGt.

Chiari, A. S. S. \& Borba, M. C. (2016). Possibilidades comunicacionais na disciplina de álgebra linear a distância a partir do uso de tecnologias digitais. Em A. J. Ribeiro e N. E. Bertoni (Eds.), Anais XII ENEM - Encontro Nacional de Educação Matemática (pp. 113). Sociedade Brasileira de Educação Matemática (SBEM). http://bit.ly/34dKUfD.

Damasceno, L. G. (1990). Aplicação de linguagens de programação em gráficos: De funções, figuras planas e espaciais. Em E. A. Toledo (Ed.), Anais III ENEM - Encontro Nacional de Educação Matemática (pp. 63). Sociedade Brasileira de Educação Matemática (SBEM). http://bit.ly/2naWWGX. 
Delizoicov, D., Castilho, N., Cutolo, L. R. A., Ros, M. A. \& Lima, A. M. C. (2002). Sociogênese do conhecimento e pesquisa em ensino: Contribuições a partir do referencial Fleckiano. Caderno Brasileiro de Ensino de Física, 19(1), 52-69. https://bit.ly/2P0FfEp.

Farias, M. R. \& Miskulin, R. G. S. (2013). As representações semióticas como abordagem para o ensino da matemática mediante uso de softwares educativos. Em C. A. Muniz e R. E. S. R. Borba (Eds.), Anais XI ENEM - Encontro Nacional de Educação Matemática (pp. 1-16). Sociedade Brasileira de Educação Matemática (SBEM). http://bit.ly/36qQIDX.

Fleck, L. (1986). La Génesis y el Desarrollo de un Hecho Científico. Alianza Editorial.

Gomes, M. D. (2016). Tecnologia da informação e comunicação: Da origem da palavra à interação do professor de matemática. Em A. J. Ribeiro e N. E. Bertoni (Eds.), Anais XII ENEM - Encontro Nacional de Educação Matemática (pp. 1-10). Sociedade Brasileira de Educação Matemática (SBEM). http://bit.ly/39zrwwB.

Klüber, T. E. (2009). Um olhar sobre a modelagem matemática no Brasil sob algumas categorias fleckianas. Alexandria: Revista de Educação em Ciência e Tecnologia, 2(2), 219-240. https://bit.ly/3g3Bzxz.

Löwy, I. (1994). Ludwik Fleck e a presente história das ciências. História, Ciências, Saúde - Manguinhos, 1(1), 7-18. https://bit.ly/3kqcfEl.

Moraes, M. C. (1993). Informática Educativa no Brasil: Um pouco de história... Em Aberto, 12(57), 17-26. http://bit.ly/2oIHQsH.

Peixoto, L. S. \& Notare, M. R. (1998). Educação Matemática e Internet: Uma proposta inovadora. Em A. Cassol, G. Knijnik, H. M. Huppfer, J. Hennemann, M. Grasselli, R. Wolff, R. J. Detsch e V. P. Silva (Eds.), Anais VI ENEM - Encontro Nacional de Educação Matemática (pp. 351). Sociedade Brasileira de Educação Matemática (SBEM). http://bit.ly/2naWWGX.

Salles, A. T. \& Bairral, M. A. (2010). Interações e aprendizagem Matemática: Um estudo de interlocuções em VMT-Chat. Em P. F. Lima e C. A. Muniz (Eds.), Anais X ENEM Encontro Nacional de Educação Matemática (pp. 1-11). Sociedade Brasileira de Educação Matemática (SBEM). http://bit.ly/2P82kFR.

Silva, P. A. L. (1992). As novas tecnologias e a Educação Matemática. Em J. V. Floriani (Ed.), Anais IV ENEM - Encontro Nacional de Educação Matemática (pp. 106). Sociedade Brasileira de Educação Matemática (SBEM). http://bit.ly/2naWWGX.

Silva, J. C. \& Souza Junior, A. J. (2001). Trabalhando com Projetos e Informática: Em busca de um caminho para o ensino com pesquisa. Em T. M. M. Campos (Ed.), Anais VII ENEM - Encontro Nacional de Educação Matemática (pp. 1-19). Sociedade Brasileira de Educação Matemática (SBEM). http://bit.ly/2naWWGX.

Souza, H. G. (1983). Informática na Educação e Ensino de Informática: Algumas Questões. Em Aberto, 17(2), 1-8. http://bit.ly/2DIOXW8.

Valente, J. A. (Ed.) (1999). O computador na sociedade do conhecimento. NIED/Unicamp. https://bit.ly/2HWyJMq. 
Autores

Victor Hugo Ricco Bone Antunes

Mestrando em Educação Matemática pela Universidade Estadual do Oeste do Paraná (Unioeste, Brasil). Integrante do Grupo de Pesquisa em Tecnologia, Inovação e Ensino.

Temas de pesquisa: Tecnologias Digitais da Informação e Comunicação (TDIC) em Educação Matemática. E-mail: antunesvictorh@gmail.com

Clodis Boscarioli

Doutor em Engenharia Elétrica pela Universidade de São Paulo (USP, Brasil). Professor Associado na Universidade Estadual do Oeste do Paraná (Brasil). Temas de pesquisas: Tecnologias Digitais na Educação Matemática; Banco de Dados e Inteligência Computacional. E-mail: clodis.boscarioli@unioeste.br

Tiago Emanuel Klüber Doutor em Educação Científica e Tecnológica pela Universidade Federal de Santa Catarina (UFSC, Brasil). Professor Associado na Universidade Estadual do Oeste do Paraná. Temas de pesquisa: Modelagem Matemática; Epistemologia e Filosofia da Educação Matemática. E-mail: thagokluber@gmail.com 